\title{
Adverse drug reactions in patients taking anti tuberculosis therapy from directly observed treatment short course centre at Mandya Institute of Medical Sciences, Mandya: a cross sectional study
}

\author{
Shambhulinga Kambale, P. Subhas Babu*, Nagaraja Goud B., Harish B. R.
}

Department of Community Medicine, Mandya Institute of Medical Sciences (MIMS), Mandya, Karnataka, India

Received: 26 November 2019

Revised: 03 January 2020

Accepted: 04 January 2020

*Correspondence:

Dr. P. Subhas Babu,

E-mail: p.subhash.babu@gmail.com

Copyright: (C) the author(s), publisher and licensee Medip Academy. This is an open-access article distributed under the terms of the Creative Commons Attribution Non-Commercial License, which permits unrestricted non-commercial use, distribution, and reproduction in any medium, provided the original work is properly cited.

\begin{abstract}
Background: Ending the tuberculosis (TB) epidemic by 2030 is among the health targets of the sustainable development goals. Side effects to anti-TB drugs are common and may lead to reduced compliance to treatment. These adverse effects must be recognized early to reduce associated morbidity and mortality. Objective of this study was to determine the adverse drug reactions (ADR) to anti-tubercular therapy among patients visiting directly observed treatment, short-course (DOTS) centre MIMS, Mandya.

Methods: A cross sectional study was conducted at DOTS Centre MIMS, Mandya. TB patients registered at DOTS Centre during the year 2018 were selected for the study. Verbal informed consent was taken from the TB patients and interviewed using pretested semi-structured questionnaire. Data analysis was done using descriptive statistics and chi square test.

Results: Among the study population ( $\mathrm{n}=90), 67(74.4 \%)$ experienced ADR among which $47.7 \%$ took treatment for ADR and the remaining $52.3 \%$ patients were given reassurance. In this study, gastrointestinal manifestations (42.3\%) were the most common adverse drug reaction (ADR). Of the TB patients who experienced ADR, $9.0 \%$ of them had interrupted ATT, however they completed full course of ATT.

Conclusions: A considerable number of TB patients taking ATT experience ADRs and some of them may have to interrupt treatment. However, they need to be counselled or supervised with caution to complete their course of treatment to reduce the chances of treatment default and also reduce the occurrence of drug resistance.
\end{abstract}

Keywords: Anti- tubercular therapy, Adverse drug reaction, Directly observed treatment short-course

\section{INTRODUCTION}

Tuberculosis (TB) is an infectious disease caused by Mycobacterium tuberculosis. TB is one of the top 10 causes of death worldwide. 10 million people fell ill with TB and 1.6 million died due to TB in the year 2017. Among HIV positive individuals TB is the leading cause of mortality. Each year 1 million children become ill with TB and more than 200,000 children die of TB. Multidrugresistant TB (MDR-TB) is a public health crisis and a health security threat. Globally, 54 million lives were saved through TB diagnosis and treatment between 2000 and 2017. Ending the TB epidemic by 2030 is among the health targets of the sustainable development goals. ${ }^{1}$

All anti-tubercular drugs can cause adverse drug reaction (ADR) during the anti-tubercular therapy (ATT). ${ }^{2}$ ATT causes ADR involving almost all systems in the body, including the gastrointestinal tract, liver, skin, nervous system, otovestibular apparatus and eyes. ${ }^{3}$ Treatment 
failure and relapse risk will increase because of drug resistance if the patient discontinues the ATT., ${ }^{4,5}$

In case, any major ADR occurs during ATT, one of the three effective drugs (isoniazid, rifampicin and pyrazinamide) must be stopped and it should be treated in hospital and ATT resumed as early as possible. ${ }^{6}$

First line ATT drugs are safe and well tolerated. ADR due to ATT are common. Compliance to ATT may be reduced because of side effects. ADR should be detected and treated early to reduce associated morbidity and mortality.

The first line ATT drugs are known to cause adverse effects like gastritis, hepatotoxicity and skin allergies. This study was done to determine the occurrence of such adverse effects in patients under directly observed treatment short course (DOTS) therapy and to assess ADR effects on patient compliance.

\section{METHODS}

A cross sectional study was conducted from May to June 2019 at DOTS Centre MIMS, Mandya. All the TB Patients registered at DOTS Centre during the year 2018 were selected in the study. In this study out of 107 TB patients, 90 patients were selected for the study according to the inclusion and exclusion criteria. Preliminary data including contact numbers of patients and DOTS providers was noted from the treatment cards available in the DOTS centre MIMS, Mandya. Informed consent was taken from the TB patients and interviewed through telephonic communication using pretested semistructured questionnaire.

\section{Inclusion criteria}

Tuberculosis patients registered at DOTS Centre, who will give informed consent to participate in the study.

\section{Exclusion criteria}

TB patients on ATT also taking treatment for other comorbidities like HTN, DM and HIV etc. are excluded from the study because those drugs can also produce ADR as well as drug interactions which may interfere with the causal inference of ADR due to ATT.

\section{Method of data collection}

Pretested semi-structured questionnaire was used. All the TB patients were interviewed for the information as specified in the questionnaire. The study variables were age, sex, education, socioeconomic status of the patient, side effects of drugs, smoking habit, alcohol consumption and other variables related to ADR. The patients were interviewed about whether the DOTS providers informed about the side effects of ATT at the time of starting ATT, the side effects experienced due to the anti-tubercular therapy, any treatment they took for those side effects and was there any history of discontinuation of ATT because of side effects.

\section{Statistical analysis}

Descriptive statistics like frequencies, proportions and inferential statistics like chi square test was used to know the association. The study was conducted after obtaining ethical clearance from institutional ethical committee.

\section{RESULTS}

In our study among total 90 TB patients, $54(60 \%)$ were males and 36 (40\%) females respectively. Most of the study participants (34.4\%) were in the age group of 31-45 years followed by $26.6 \%$ in the age group of $16-30$ years (Table 1).

Table 1: Distribution of TB patients according to age and $\operatorname{sex}(n=90)$.

\begin{tabular}{|llll|}
\hline $\begin{array}{l}\text { Age group } \\
\text { (years) }\end{array}$ & $\begin{array}{l}\text { Sex } \\
\text { Female (\%) }\end{array}$ & Male (\%) & Total (\%) \\
\hline $\mathbf{0 - 1 5}$ & $03(60.0)$ & $02(40.0)$ & $05(05.5)$ \\
\hline $\mathbf{1 6 - 3 0}$ & $12(50.0)$ & $12(50.0)$ & $24(26.6)$ \\
\hline $\mathbf{3 1 - 4 5}$ & $12(38.7)$ & $19(61.3)$ & $31(34.4)$ \\
\hline $\mathbf{4 6 - 6 0}$ & $05(25.0)$ & $15(75.0)$ & $20(22.3)$ \\
\hline $\mathbf{> 6 0}$ & $04(40.0)$ & $06(60.0)$ & $10(11.2)$ \\
\hline Total & $36(40.0)$ & $54(60.0)$ & $90(100.0)$ \\
\hline
\end{tabular}

The majority of TB patients $(51.2 \%)$ had studied up to primary level and $22.2 \%$ up to high school level. $13.4 \%$ TB patients were illiterate (Table 2).

Table 2: Distribution of TB patients according to education and $\operatorname{sex}(n=90)$.

\begin{tabular}{|llll|}
\hline Education & \multicolumn{1}{l}{ Sex } & & Total (\%) \\
\hline Illiterate & Female (\%) & Male (\%) & \\
\hline Primary school & $17(36.9)$ & $29(63.1)$ & $46(51.2)$ \\
\hline High school & $04(20.0)$ & $16(80.0)$ & $20(22.2)$ \\
\hline Pre- university & $05(83.3)$ & $01(16.7)$ & $06(06.6)$ \\
\hline Degree & $05(83.3)$ & $01(16.7)$ & $06(06.6)$ \\
\hline Total & $36(40.0)$ & $54(60.0)$ & $90(100)$ \\
\hline
\end{tabular}

Males commonly experienced ADR as compared to females. ADR like GIT adverse effects (60.6\%), joint pain $(64.3 \%)$, peripheral neuropathy $(60 \%)$ and skin rashes $(64.7 \%)$ were found in males, however the occurrence of dizziness were found to be equal in both males and females (Table 3).

In our study $38(42.3 \%)$ patients experienced gastrointestinal side effects, among them 30 (78.9\%) had pulmonary TB and $8(21.1 \%)$ had extra-pulmonary TB. $14(15.5 \%)$ study subjects complained of joint pain after 
taking ATT and $20(22.2 \%)$ of them had peripheral neuropathy. $17(18.9 \%)$ and $8(8.9 \%)$ of them developed skin rashes and dizziness respectively (Table 4). A total $20 \%$ of study subjects gave history of tobacco use, among them $88.8 \%$ experienced ADR due to ATT. $24 \%$ of study subjects gave history of alcohol consumption, among them $81.8 \%$ experienced ADR due to ATT.

Table 3: Sex wise distribution of patients with adverse drug reactions (ADR) due to ATT (n=90).

\begin{tabular}{|c|c|c|c|c|c|}
\hline \multirow[b]{2}{*}{ ADR due to ATT } & \multirow[b]{2}{*}{$\begin{array}{l}\text { ADR } \\
\text { (yes or no) }\end{array}$} & \multicolumn{2}{|l|}{ Sex } & \multirow[b]{2}{*}{ Total (\%) } & \multirow[b]{2}{*}{$P$ value } \\
\hline & & $\begin{array}{l}\text { Females }(\%) \\
(n=36)\end{array}$ & $\begin{array}{l}\text { Males }(\%) \\
(\mathrm{n}=54)\end{array}$ & & \\
\hline \multirow{2}{*}{$\begin{array}{l}\text { GIT adverse } \\
\text { effects }\end{array}$} & Yes & $15(39.4)$ & $23(60.6)$ & 38 (42.3) & \multirow{2}{*}{0.931} \\
\hline & No & $21(40.3)$ & $31(59.7)$ & $52(57.7)$ & \\
\hline \multirow{2}{*}{ Joint pain } & Yes & $05(35.7)$ & $09(64.3)$ & $14(15.5)$ & \multirow{2}{*}{0.722} \\
\hline & No & $31(40.7)$ & $45(59.3)$ & $76(84.5)$ & \\
\hline \multirow{2}{*}{$\begin{array}{l}\text { Peripheral } \\
\text { neuropathy }\end{array}$} & Yes & 08 (40.0) & $12(60.0)$ & $20(22.2)$ & \multirow{2}{*}{1.000} \\
\hline & No & $28(40.0)$ & $42(60.0)$ & 70 (77.8) & \\
\hline \multirow{2}{*}{ Skin rashes } & Yes & $06(35.3)$ & $11(64.7)$ & 17 (18.9) & \multirow{2}{*}{0.660} \\
\hline & No & $30(41.0)$ & $43(59.0)$ & $73(81.1)$ & \\
\hline \multirow{2}{*}{ Dizziness } & Yes & $04(50.0)$ & $04(50.0)$ & $08(08.9)$ & \multirow{2}{*}{0.545} \\
\hline & No & $32(39.0)$ & $50(61.0)$ & $82(91.1)$ & \\
\hline
\end{tabular}

Table 4: Distribution of patients with adverse drug reactions (ADR) due to ATT among pulmonary TB and extrapulmonary TB $(\mathbf{n}=90)$.

\begin{tabular}{|c|c|c|c|c|c|}
\hline \multirow[b]{2}{*}{ ADR due of ATT } & \multirow[b]{2}{*}{$\begin{array}{l}\text { ADR } \\
\text { (yes or no) }\end{array}$} & \multicolumn{2}{|l|}{ Type of tuberculosis } & \multirow[b]{2}{*}{ Total $(\%)$} & \multirow[b]{2}{*}{$P$ value } \\
\hline & & $\begin{array}{l}\text { Pulmonary TB (\%) } \\
(n=71)\end{array}$ & $\begin{array}{l}\text { Extra-pulmonary TB (\%) } \\
(\mathrm{n}=19)\end{array}$ & & \\
\hline \multirow{2}{*}{$\begin{array}{l}\text { GIT adverse } \\
\text { effects }\end{array}$} & Yes & 30 (78.9) & 08 (21.1) & $38(42.3)$ & \multirow[b]{2}{*}{0.991} \\
\hline & No & $41(78.8)$ & $11(21.2)$ & $52(57.7)$ & \\
\hline \multirow{2}{*}{ Joint pain } & Yes & $11(78.5)$ & $03(21.5)$ & $14(15.5)$ & \multirow[b]{2}{*}{0.975} \\
\hline & No & $60(78.9)$ & $16(21.1)$ & $76(84.5)$ & \\
\hline \multirow{2}{*}{$\begin{array}{l}\text { Peripheral } \\
\text { neuropathy }\end{array}$} & Yes & $15(75.0)$ & $05(25.0)$ & $20(22.2)$ & \multirow{2}{*}{0.629} \\
\hline & No & $56(80.0)$ & $14(20.0)$ & $70(77.8)$ & \\
\hline \multirow{2}{*}{ Skin rashes } & Yes & $13(76.4)$ & $04(23.6)$ & $17(18.9)$ & \multirow{2}{*}{0.786} \\
\hline & No & $58(79.4)$ & $15(20.6)$ & $73(81.1)$ & \\
\hline \multirow{2}{*}{ Dizziness } & Yes & $05(62.5)$ & $03(37.5)$ & $08(8.9)$ & \multirow{2}{*}{0.234} \\
\hline & No & 66 (80.4) & 16 (19.6) & 82 (91.1) & \\
\hline
\end{tabular}

Table 5: Interruption of ATT due to ADR among TB patients $(\mathrm{n}=67)$.

\begin{tabular}{|ll|}
\hline Interruption of ATT due to ADR & Frequency (\%) \\
\hline Yes & $06(09.0)$ \\
\hline No & $61(91.0)$ \\
\hline Total & $67(100.0)$ \\
\hline
\end{tabular}

Of those who experienced ADR [n=67 (74.4\%)], among them $6(9.0 \%)$ had interrupted taking ATT because of its ADR. However, they completed full course of ATT after receiving reassurance regarding common side effects of ATT from DOTS providers (Table 5).

\section{DISCUSSION}

In our study, we found that the gastrointestinal manifestations $42.3 \%$ were the most common adverse drug reaction (ADR) followed by peripheral neuropathy
$22.2 \%$, skin rashes $18.9 \%$ joint pain $15.5 \%$ and dizziness $8.9 \%$.

A study conducted by Singh et al also found gastrointestinal manifestations $42.3 \%$ as most common ADR followed by genito-urinary symptoms (32\%), joint pain (13\%), central nervous system 7\%, skin rashes 6\%, vestibulo-ocular symptoms $3 \%{ }^{8}$

Dhingra et al reported that gastrointestinal reactions like nausea and vomiting (53\%) was the commonest side effect followed by, general aches and pains (35\%), giddiness $(27 \%)$, skin reactions $(17 \%)$ and joint pain $(11 \%)$. while only $1 \%$ had hepatotoxicity during treatment. ${ }^{9}$

Similar finding was found by Tak et al Priyadarshini et al and Tag EI Din et al in their studies. ${ }^{10-12}$ However, the Bhattarai et al, Kurniawati et al and Schaberg et al 
reported that joint pain, skin reactions and hepatotoxicity as the most common ADR due to ATT respectively. ${ }^{13-15}$

In this study, $74.4 \%$ experienced ADR among which $47.7 \%$ taken treatment for ADR and remaining 52.3\% patients were reassured. Of the TB patients who experienced ADR, 9.0\% of them had interrupted ATT, however they completed full course of ATT. According to the study conducted by Bhattarai et al, $83.9 \%$ of the patients experienced ADR during ATT. ${ }^{13}$ Kurniawati et al stated that, $15.8 \%$ patients had ADR in which $8.6 \%$ patients took medication for it and $6.1 \%$ patients interrupted ATT. ${ }^{14}$

The occurrence of ADR due to ATT may be influenced by several risk factors. In the present study, patients who had history of alcohol consumption and smoking experienced more ADR. Similar finding were found in the studies conducted by Bhattarai et al and Kurniawati et al. ${ }^{13,14}$ A research done by Schaberg et al found that $23 \%$ patients interrupted ATT because of severe ADR mainly pyrazinamide induced hepatotoxicity. ${ }^{15}$

\section{CONCLUSION}

Gastrointestinal manifestations (42.3\%) were the most common ADR in this study. ADR were experienced by $74.4 \%$ TB patients, out of which $47.7 \%$ took treatment for ADR and remaining 52.3\% patients were counselled and given reassurance. Of the TB patients who experienced ADR, 9.0\% of them had interrupted ATT, however they completed full course of ATT.

It is a need for early recognition and treatment of ADR that occurs during course of ATT to decrease the morbidity and mortality which may result from drug resistance because of interruption of ATT due to ADR.

In our study telephonic communication was used to interview the TB patients regarding the ADR experienced during ATT. No Biochemical or other investigations are done to measure ADR like hepatotoxicity, ototoxicity, nephrotoxicity and disturbances in color vision. These were the limitations of this study.

\section{ACKNOWLEDGEMENTS}

Authors would like to thank District TB Office (DTO), Mandya, Karnataka, and DOTS Centre MIMS, Mandya, Karnataka.

Funding: No funding sources

Conflict of interest: None declared

Ethical approval: The study was approved by the Institutional Ethics Committee

\section{REFERENCES}

1. Burden of tuberculosis. Available at: https://www.who.int/news-room/fact-sheets/detail/ tuberculosis. Accessed on $22^{\text {nd }}$ May 2019.

2. Bedi RS. Pyrazinamide- induced hypersensitivity reaction. Indian J Tuber. 1990;37:41.

3. Tandon RK, Garg PK. Antituberculosis treatment induced hepatotoxicity. In: Sharma. S K, Mohan, Tuberculosis. New Delhi: Jaypee Brothers; 2004: 500.

4. American Thoracic Society. Treatment of tuberculosis and tuberculosis infection in adults and children. Am J Respir Crit Care Med. 1994;149:1359-74.

5. Ormerod LP. Chemotherapy and management of tuberculosis in the United Kingdom: recommendations of the Joint Committee of the British Thoracic Society. Thorax. 1990;45:403-8.

6. Xia YY, Hu DY, Liu FY, Wang XM, Yuan YL, Tu DH. Design of the anti-tuberculosis drugs induced adverse reactions in China national Tuberculosis prevention and cotroscheme study. BMC Public Health. 2010;10:267-76.

7. Revised national TB control programme technical and operational guidelines for tuberculosis control in India 2016. Available at: https://tbcindia.gov. in/showfile.php?lid=3197. Accessed on $22^{\text {nd }}$ May 2019.

8. Singh AK, Pant N. Adverse effects of first line antitubercular medicines on patients taking directly observed treatment short course: A hospital-based study. Inter J Med Pub Health. 2014;4(4):354-8.

9. Dhingra VK, Rajpal S, Aggarwal N, Aggarwaln JK, Shadab K, Jain SK. Adverse drug reactions observed during DOTS. J Commun Dis. 2004;36:251-9.

10. Tak DK, Acharya LD, Gowrinath K, Rao Padma GM, Subish P. Safety evaluation of antitubercular therapy under revised National Tuberculosis Control Programme In India. J Clin Diag Res. 2009;3(2):1395-401.

11. Priyadarshini Bai G, Ravikumar P. A study on treatment outcome and adverse drug reactions among extra pulmonary tuberculosis patients treated under DOTS in a tertiary care hospital. Inter J Basic Clin Pharmacol. 2017;6(1):48-52.

12. Mohammad A. Tag EI Din. Ashraf A, EI Maraghy, Abdel Hay R, Hay A. Adverse reactions among patients being treated for multi-drug resistant tuberculosis at Abbassia Chest Hospital. Egypt J Chest Dis Tuber. 2015:939-952.

13. Bhattarai S, Thapa P, Shrestha C, Dangol S, Niroula T, Verma SC. A study on socio-demographic pattern and side effects of anti-tubercular drugs among tuberculosis patients in pokhara valley. SAARC J Tuber Lung Dis HIV/AIDS. 2013;10(2):41-4.

14. Kurniawati F, Syed Sulaiman SA, Gillani SW. Adverse drug reactions of primary anti-tuberculosis 
drugs among tuberculosis patients treated in chest clinic. Int J Pharm Life Sci. 2012;3:976-7126.

15. Schaberg TK, Rebhan, Lode H. Risk factors for side effects of isoniazid, rifampin and pyrazinamide in patients hospitalized for pulmonary tuberculosis. Eur Respir J. 1996;9:2026-30.
Cite this article as: Kambale S, Babu PS, Goud BN, Harish BR. Adverse drug reactions in patients taking anti tuberculosis therapy from directly observed treatment short course centre at Mandya Institute of Medical Sciences, Mandya: a cross sectional study. Int J Community Med Public Health 2020;7:620-4. 